\title{
Gaussian Prediction Method to Enhance Energy Efficient in Energy Aware AODV
}

\author{
Muhammad Arief Hidayat ${ }^{1, *}$, Aghus Sofwan ${ }^{2}$ and Agung Budi Prasetijo ${ }^{2}$ \\ ${ }^{1}$ Department of Electrical and Electronics Engineering Diponegoro University, Semarang - Indonesia \\ ${ }^{2}$ Department of Computer Engineering Diponegoro University, Semarang - Indonesia
}

\begin{abstract}
One of the concerns in the development routing protocol in Mobile Ad Hoc Network is energy consumption which is very influential on package delivery. Energy Delay Aware Ad hoc Demand on Distance Vector (EA-AODV) is one of the routing protocols for the development of Ad hoc Demand on Vector (AODV) that considers energy when receiving packets stored in the routing table. The routing protocol applies the Dijkstra algorithm to determine the shortest route by considering the sequence number and hop count. In the development carried out on EA-AODV is a modification of the Dijkstra algorithm by adding a gaussian prediction method in consideration of the energy level that is expected to be more efficient in terms of energy consumption. Gaussian prediction method was executed in receive request (RREQ) when the packet saved in the routing table. The Application of the network protocol was conducted by comparing the performance of AODV with EA-AODV. The consumption energy of EAAODV is more efficient at $12.07 \%$ compared to AODV.
\end{abstract}

Keywords: EA-AODV; Dijkstra Algorithm; Gaussian prediction method; NS2.35.

\section{Introduction}

MANET (Mobile Ad Hoc Network) is a wireless ad hoc network that is created by nodes connected via wireless networks. It consists of two groups based on performance, namely the reactive routing protocol and proactive routing protocol. The reactive protocol is a part of the routing protocol that does not need periodic routing table updates that are applied to the Ad hoc OnDemand Vector routing protocol and Dynamic Source Routing [1-3]

AODV is a routing protocol to select the shortest path to reach the destination node based on hop count and sequence when the node sends the packet to destination node called Dijkstra method $[4,5]$. In the AODV routing protocol, the packet sending process from source node will initialize the route discovery process that begins by broadcasting route requests (RREQ) to neighbor nodes until the packet is received to the destination node. The node will send route reply (RREP) if the route that is passed has the lowest hop while the other node with more hops will be discarded [6]. If the node cannot forward the packet because the node is broken, then the node will send route error (RRER) [7]. The process is to improve routing protocol performance based on throughput efficiency [8-11].

Energy is a concern in the developt of routing protocol, these articles [12-15] that consider this in their proposed method consider to maximize energy efficiency and increase throughput. In [16], energy efficiency was carried out with various methods, one of which was to set threshold value as a consideration of energy residues. So that research is done by changing route discovery to consider energy efficient consumption on the process of receiving RREQ packets on the AODV protocol to improve energy efficiency.

The Gaussian probability distribution is a method to predict the value of two class hypothesis testing problem $[17,18]$. This method is used to consider the threshold of energy residue. It could process in RREQ when node considers the shortest path.

\section{Literature review}

Energy consumption is required in the packet sender from the source node to the destination node that is applied in the study [12] to analyze the performance of AODV based on the mobility model consisting of the Random Way Point Model, Gauss Markov Model, and Manhattan Mobility Model.

In [19] Mohammed Aashkar proposed the Energy Efficient AODV method which is the development of AODV by implementing the Euclidean equation. The method is done by determining the value associated with the time to send a packet from the original node to the destination node. The proposed method is applied to the routing protocol with an area of $1000 \mathrm{~m} \times 1000 \mathrm{~m}$ using CBR traffic on node 30 with type MAC802.11 which is simulated by using network simulator software 2.35 .

In [20] N. Ket proposed AODVM (AODV MODIFIED) is a development of AODV Energy Aware

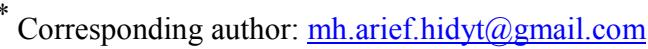


(AODVEA), the selection of nodes based on the threshold. The process was carried out when the node sends RREQ to an adjacent node by initializing remaining energy. If the node has less remaining energy, then the value was divided by hop count to obtain $\alpha$. If the value of $\alpha$ was maximum, then the node will send RREP. The AODVM method was carried out on CBR traffic with an area of $700 \mathrm{~m} \times 700 \mathrm{~m}$ and the number of nodes 50, where the receiving power and transmission power of nodes were $300 \mathrm{~mW}$ and $600 \mathrm{~mW}$.

In [21] and [22] H. Y. Swe proposed a method by modifying the AODV routing protocol based on energy by adding new parameters to the routing table, namely energy factor and node lifetime. These parameters were used when nodes send RREQ to adjacent nodes, the origin node will calculate the energy factor and network lifetime, after that process the node broadcast message. The energy factor value obtained from residual energy was divided by initial energy from the node, while network lifetime is obtained from the remaining energy received by the node when sending RREQ or RREP minus the remaining energy when receiving RREQ and RREP. The node will send RREP if the node has a higher EF and NLT value. In addition to the EF and NLT values, the node selects a route based on hop count. The method is applied to an area of $670 \times 760$ with a number of varied nodes, namely 100, 150, 200, 250 with MAC 802.11 and 300 types with 30 TCP traffic numbers.

In [16] by K.Mariappan, Dr has proposed the method of NRE-AODV (Residual Energy - AODV Node) by modifying RREQ for the discovery route process by adding Minimum Residual Energy (MRE) and Sum of Residual Energy (SRE). Where the average SRE was calculated from the sum of energy residues divided by the number of hops while MRE was calculated from the minimum average of the energy residue of the node divided by the number of hops. The MRE and SRE process was carried out if the packet RREQ has a larger sequence number otherwise, the packet will not be forwarded. In the RREQ receiver process, the routing packet calculates the energy difference obtained by comparing the MRE value to the threshold, if MRE was greater than the threshold then SRE divided by hop count was reduced by the threshold otherwise MRE divided by hop count reduced by the threshold. Energy difference values are used to select routes based on the routing table. This research was conducted in an area of $1500 \mathrm{~m} \times 1500 \mathrm{~m}$ with a number of nodes 100 and moving based on a random waypoint model with a node speed of $20 \mathrm{~m} / \mathrm{s}$ by sending a packet of 512 with the type of CBR traffic and energy initialization nodes of 60 and 200 Joules.

Based on the research, an energy efficient process is carried out at the RREQ AODV. From this process, we propose the Bayesian method to determine the threshold value of energy. This method is carried out on packet reception when choosing a route based on the routing table.

\section{Dijkstra algorithm}

The Dijkstra algorithm is an algorithm to assign the shortest path to reach the destination. In the AODV routing protocol, the shortest distance determination performed when discovery route RREQ was received by node [23].

\section{Algorithm design method}

In the AODV process, a source node broadcast packet that contains an IP address, sequence number, and hops count through the route that is passed to the destination node. The destination node or neighbor will send RREP if those node receives the first RREQ packet and has a minimum hop count. In addition, to consider the hop count for sending RREP, the node also consider the sequence number that saved in the routing table.

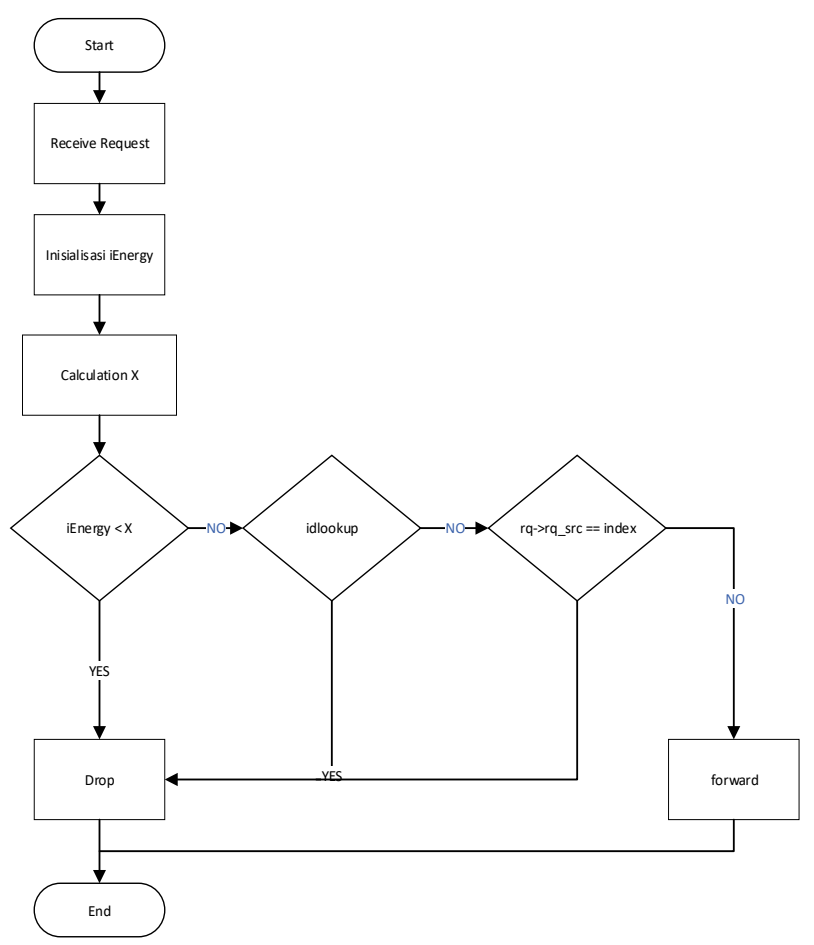

Fig. 1. Receive request process

Based on the AODV process, we develop AODV that considers energy efficiency and lower delay time. This process was carried out when the node initializes the reception of RREQ. Where the node compares the residual energy from the node obtained when the node receives the RREQ and RREP packages indicated by equation 1 with generating a random value. If the energy residue is less than the generated random value, the packet would not be forwarded. Otherwise, the node has greater than the generated random value, the node will consider hop count and sequence number. In addition to considering energy residues, the node chooses a route based on the hop count and the seq number stored in the routing table. The EA-AODV process is described in Fig 1. 


\section{Remain Energy = Initial Energy - Receive energy}

Energy Receive is energy consumption when the node receives packets per second [24].

The Gaussian prediction method in the routing protocol is obtained from by the formula below:

Generate random value of Gaussian prediction ${ }_{n}=$ $\mu+\sum X_{f_{1} / 2} \times \sin (y)$

The value of $X_{h_{1} \delta_{2}}$ is the random value of initial energy used from $0-50$, and $y$ is $2 \times \pi \times X_{f_{2}}$

\section{Simulation and result}

In this model, we perform simulation in order to show our protocol proposes that has good performance. It was evaluated by comparing EA-AODV with AODV based on the parameters as below on Table 1.

Table 1. Simulation parameter

\begin{tabular}{|l|l|}
\hline $\begin{array}{l}\text { Parameter } \\
\text { simulation }\end{array}$ & value \\
\hline Number of node & $10,20,30,40$, and 50 node \\
\hline Size packet & $512 \mathrm{Kbps}$ \\
\hline Traffic Model & $\mathrm{CBR}$ \\
\hline Initial Energy & 50 \\
\hline Receive Energy & 5 \\
\hline Transmit Energy & 10 \\
\hline Area & $1500 \times 1500$ \\
\hline
\end{tabular}

Simulations of parameters indicated in Table 1 are carried out using NS-2.35 software with a simulation time of 1800 seconds. The simulation results are processed using awk to calculate delay, throughput, pdr, and average residual energy.

\section{Throughput}

Throughput is data received by nodes that are implemented at the start time until the end time. The formula to calculate throughput were shown on formula 3 as follows:

$$
\text { Throughput }=\frac{\text { Packet received" gize packet"g }}{\text { time }}
$$

\section{Packet delivery ratio}

PDR is the success of the packet received by the destination node from packets were sent by the source node. Formula to calculate PDR were shown in formulas 4 as follows:

$$
P D R=\frac{\text { number of Packet received }}{\text { number of Packet sent }} \times 100 \%
$$

\section{Delay}

Delay is the time difference between the node sending the packet and the time the node receives the packet. The formula to calculate delay were shown on formula 5 as follows:

$$
\text { Delay }=\text { st packet send }- \text { et packet received }
$$

Where st packet send is the initial time the packet is sent and et packet received is the end of the packet received.

\section{Average residual energy}

Average residual energy is the average energy remaining of each node while it receives RREQ. The formula to calculate average residual energy was shown on formula 6 as follows:

$$
\text { Average residual energy }=\frac{\text { InE-ErEn }}{\sum_{i=0}^{M} \text { nod }_{i}}
$$

Based on the above formula it is used to calculate the results of the trace file simulation that is run. The results of the formula calculated based on the average of examine 10 literation.

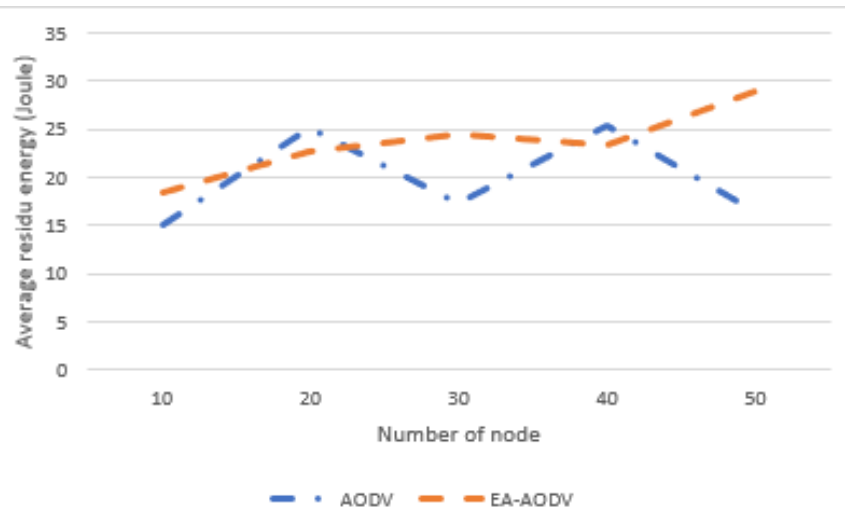

Fig 2. Result in average residue energy by comparing AODV and EA-AODV

The energy efficiency level of EA-AODV is more efficient by increasing the node density than AODV which showed in Fig 2. We can take some samples such as in the node density were 30, the energy efficiency level of EA-AODV was higher by 24.43328 joules than AODV by 17.36653 joules. Due to the packet delivery, the node considers the energy level to find the shortest path until the packet received by the destination node.

In Fig 3. Shown the successful node in receiving a packet of both routing protocol that is increasing in the high node density. It's due to both routing protocols that have packet delivery based on finding the shortest path. In the node density are 30 , the pdr result of EA-AODV is higher by 81.97606 percent than AODV by 25.76554 percent. This due to EA-AODV considers energy consume level to find the shortest path in the packet delivery to the destination node.

Delay in EA-AODV is lower than AODV because EA-AODV considers based on a method to find the shortest path. This is shown in Fig 4, for the node density was 30, EA-AODV has delay is lower by 0.149454 seconds than AODV by 0.871192 seconds. 


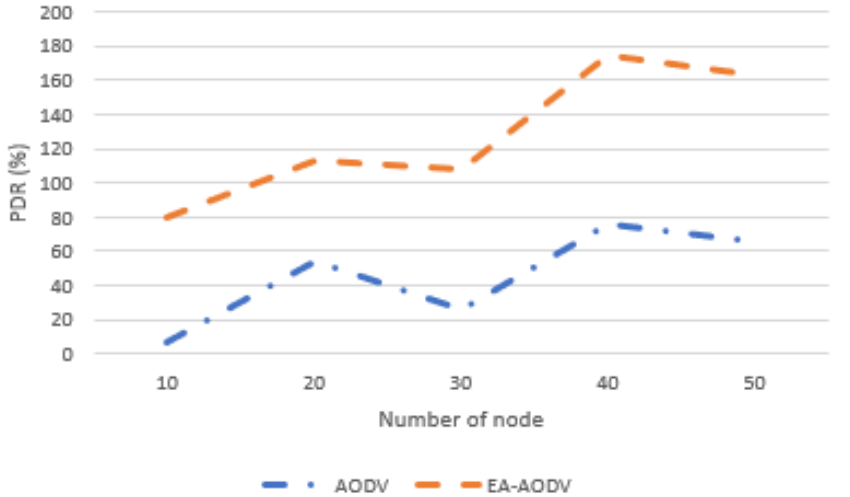

Fig 3. Result in PDR by comparing AODV and EA-AODV

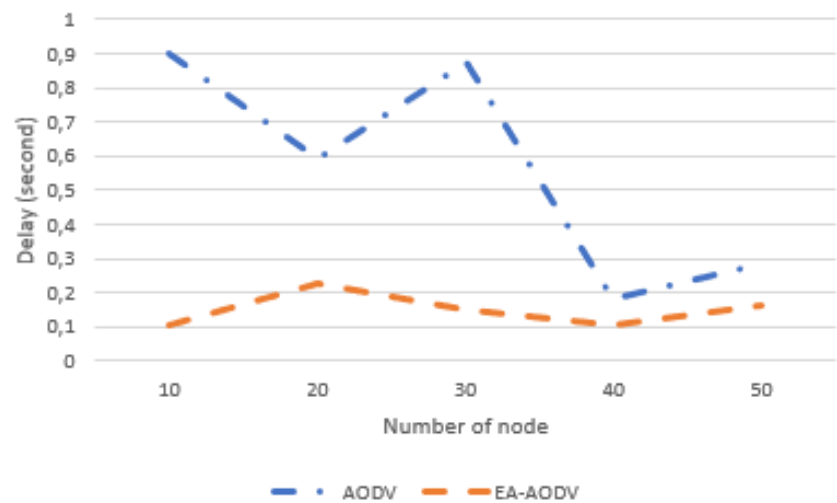

Fig 4. Result in delay by comparing AODV and EA-AODV

\section{Conclusion}

EA-AODV is the development of the AODV routing protocol that changes the packet reception process which taking into account the comparison of randomly generate values with energy residues. In this study, the Dijkstra algorithm process was added to this process to determine the shortest path to the destination node. We obtained that the level of efficiency from the EA-AODV routing protocol is higher than that of AODV.

\section{References}

1. W. Al-Mandhari et al., Ad-hoc On Demand Distance Vector (AODV) performance enhancement with active route time-out parameter, WSEAS Trans. Commun. 7 no. 9, 912-921 (2008)

2. M.H. Rehmani et al., A Tutorial on the Implementation of Ad-hoc On Demand Distance Vector ( AODV) Protocol in Network Simulator ( NS-2 ), (2009)

3. G. Mohandas et al., Survey on routing protocols on mobile adhoc networks, Int. Mutli-Conference Autom. Comput. Commun. Control Compress. Sens., 514-517 (2013) Online.. Available: http://ieeexplore.ieee.org/lpdocs/epic03/wrapper.ht $\mathrm{m}$ ?arnumber $=6526467$.

4. C. Pathak et al., Ad-hoc on demand distance vector routing protocol using Dijkastra's algorithm (AODV-D) for high throughput in VANET (Vehicular Ad-hoc Network), 11th Int. Conf. Ind.
Inf. Syst., 355-359 (2016) Online.. Available: http://ieeexplore.ieee.org/document/8262965/.

5. E. Suherman, Simulasi algoritma dijkstra pada protokol routing open shortest path first, 1-5

6. S.L. Meshram, P.D. Dorge, Design and Performance Analysis of Mobile Ad Hoc Network with Reactive Routing Protocols, 443-447 (2017)

7. M. Thamizhmaran, K. Arivazhagan, A. Devi, Anitha, A location prediction-based reactive routing protocol to minimize the number of route discoveries and hop count per path in mobile ad hoc networks, Comput. J. 52 no. 4, 461-482 (2015) Online.. Available: 10.1093/comjnl/bxn05

8. P. K. Sharma, A Throughput Efficient On-Demand Steering Procedure for Mobile Ad Hoc Networks, Int. Conf. Intell. Sustain. Syst. no. Iciss, 1010-1015 (2017)

9. A. Junnarkar, D. Bagwan, Efficient Algorithm and Study of QoS-Aware Mobile Ad Hoc Network Methods, ICEI 2017, 455-464 (2017) Online.. Available: 10.1007/s10846-013-9939-y.

10. H. Zhao et al., Calculating End-to-End Throughput Capacity in Wireless Networks with Consideration of Hidden Nodes and Multi-rate Terminals (2011)

11. P. Rohal et al., Study and Analysis of Throughput, Delay and Packet Delivery Ratio in MANET for Topology Based Routing Protocols ( AODV , DSR and DSDV), 1 no. Ii, 54-58 (2013)

12. P. Kumar et al., Impact of Mobility on Energy Consumption of AODV Protocol for Routing in Mobile Ad Hoc Networks, Wcsp2017 (2017)

13. G. Pujolle, Energy Efficient Routing in Wireless Ad Hoc Networks, 00 no. c, 4057-4061 (2004)

14. S. Sridhar et al., Energy supported AODV ( $E N-$ $A O D V$ ) for QoS routing in MANET, Procedia - Soc. Behav. Sci. 73, 294-301 (2013) Online.. Availablehttp://dx.doi.org/10.1016/j.sbspro.2013.02. 055 .

15. A.P. Patil et al., An Improved Energy Efficient AODV Routing Protocol for MANETs, 1-5 (2014)

16. D.M.K.K. Mariappan, NRE-AODV Routing Protocol to Maximize Network Lifetime of MANET Based on AODV, 13122-13142 (2017) Online.. Available: 10.15680/IJIRCCE.2017.

17. J.H. Kim et al., Method to improve the performance of the adaboost algorithm using gaussian probability distribution, Int. Conf. Control. Autom. Syst. ICCAS 2008, 1749-1752 (2008) Online.. Available: 10.1109/ICCAS.2008.469451

18. M.D. DeVore, Estimates of error probability for complex Gaussian channels with generalized likelihood ratio detection, IEEE Trans. Pattern Anal. Mach. Intell. 27 no. 10, 1580-1591 (2005) Online.. Available: 10.1109/TPAMI.2005.198.

19. M. Aashkaar, Enhanced Energy Efficient AODV Routing Protocol for MANET, 0-4 (2016)

20. N. Ket, Modified AODV Energy Aware Routing for Optimized Performance in Mobile Ad-hoc Networks, 1030-1034 (2016)

21. C. Technology, P.O. Lwin, Modified AODV with Energy Metrics for Wireless Sensor Network, 03 no. 35, 6960-6963 (2014) 
22. H.Y. Swe, S.S. Khaing, Modified Energy Constraint AODV for Wireless Sensor Network, 326-329 (2014)

23. M. Thamizhmaran, K. Arivazhagan, A. Devi, Anitha, Co-operative analysis of Proactive and Reactive Protocols Using Dijkstra's Algorithm, ISCO (2015)

24. A. Ndlovu, Improved Energy Efficient AODV Routing using K-means Algorithm for Cluster Head Selection, 4 no. 8 (2015) 